\title{
Serum SOX11 promoter methylation is a novel biomarker for the diagnosis of Hepatitis B virus-related hepatocellular carcinoma
}

\author{
Y. TENG ${ }^{1}$, Y. C. FAN ${ }^{1,2}$, N. N. MU ${ }^{3}$, J. ZHAO ${ }^{1}$, F. K. SUN ${ }^{1}$, K. WANG ${ }^{1,2, *}$ \\ ${ }^{1}$ Department of Hepatology, Qilu Hospital of Shandong University, Jinan 250012, China; ${ }^{2}$ Institute of Hepatology, Shandong University, Jinan \\ 250012, China; ${ }^{3}$ Department of Ultrasound, The General Hospital Jinan Military Region, Jinan 250031, China
}

*Correspondence: wangdoc876@126.com,wangdoc2010@163.com

Received October 29, 2015 / Accepted February 1, 2016

\begin{abstract}
Promoter methylation of tumor suppressor gene SOX11 has been reported to contribute to the diagnosis and prognosis of various cancerous diseases, including gastric cancer, hematopoietic malignancies and nasopharyngeal carcinoma. However, there is no data on the diagnostic potential of serum SOX11 promoter methylation in hepatocellular carcinoma (HCC). This study was therefore aimed to investigate the potential role of serum SOX11 promoter methylation as a noninvasive biomarker in the diagnosis of patients with hepatitis B virus (HBV) associated HCC. A total of 205 subjects were retrospectively included, which consisted of 111 HCC patients, 66 chronic hepatitis B (CHB) and 28 healthy controls (HCs). Methylation of SOX11 promoter was determined by methylation-specific polymerase chain reaction. The methylation frequency of serum SOX11 promoter in HCC patients $(69.4 \%, 77 / 111)$ was significantly higher than that in CHB patients $\left(13.6 \%, 9 / 66 ; \chi^{2}=51.467\right.$, $P<0.001)$ and HCs $\left(10.7 \%, 3 / 28 ; \chi^{2}=31.489, P<0.001\right)$. There was significant difference of serum SOX11 promoter methylation in HCC patients with vascular invasion $(49 / 58)$ and those without vascular invasion $\left(28 / 53 ; \chi^{2}=13.058, P<0.001\right)$. Furthermore, the sensitivity of $69 \%$ was identified for SOX 11 methylation in discriminating HCC from CHB, which was significant higher than the sensitivity of $57 \%$ for serum alpha-fetoprotein (AFP) $(P<0.05)$. Notably, SOX11 promoter methylation plus AFP showed a sensitivity of $85 \%$ in discriminating HCC from CHB. These results suggested that serum SOX11 promoter methylation might serve as a useful and noninvasive biomarker for the diagnosis of HCC.
\end{abstract}

Key words: SOX11, biomarker, DNA methylation, serum, hepatocellular carcinoma

Hepatocellular carcinoma (HCC) is the sixth most prevalent malignancy and the second leading cause of cancer related mortality worldwide $[1,2]$. HCC is usually associated with chronic infection of hepatitis $B$ virus (HBV) and hepatitis $\mathrm{C}$ virus [3]. Annually, there are nearly 750,000 newly identified HCC patients [4] and most of them die within one year after the onset of diagnosis [5]. Currently, ultrasonography and alpha fetoprotein (AFP) are the main tools for the early diagnosis of HCC $[6,7]$. However, ultrasonography is insufficient

\footnotetext{
Abbreviations: AASLD - American Association for the Study of Liver Diseases; AFP - alpha fetoprotein; AUROC - area under the receiver operating characteristic curve; $\mathrm{CHB}$ - chronic hepatitis B; FN - false negative; FP - false positive; HbsAg - hepatitis B surface antigen; HBV - hepatitis B virus; HCC - hepatocellular carcinoma; HCs - healthy controls; MSP methylation-specific polymerase chain reaction; NPV - negative predictive value; $\mathrm{PPV}$ - positive predictive value; $\mathrm{SOX}$ - Sry-related HMG box; TN - true negative; $\mathrm{TP}$ - true positive.
}

for the diagnosis of small tumor, particularly in cirrhotic liver [8]. Serum AFP level lacks adequate sensitivity and specificity for early diagnosis of HCC. The prognostic role of AFP may be influenced by the size and number of HCC nodules $[9,10]$. Almost one-third of early-stage HCC with small tumors $(<3$ $\mathrm{cm}$ ) were negative for AFP [11]. Therefore, AFP could not be a satisfied biomarker for the early diagnosis of HCC [12]. Therefore, new effective biomarkers for the early detection of HCC are urgently needed [13].

Methylation of gene promoter is a main kind of epigenetic alternations and involves in the development and progression of cancerous diseases [14-16], such as lung, gastric, bladder, prostate and breast cancers [17-19]. DNA methylation is a early cancer event and could be even detected as early as 9 years ahead of the diagnosis onset of cancer [20]. Therefore, methylation of serum gene promoters might act as a potential biomarker for early diagnosis of cancer. Methylations of 
serum IGFBP7 [13], RASSF1A [20, 21], P15 [20, 22] and $P 16$ $[23,24]$ have been reported to be promising and noninvasive biomarkers for the early detection of HCC.

SOX11 gene encodes a member of the group C SOX (SRYrelated HMG-box) transcription factor family which involved in the regulation of embryonic development and in the determination of cell fate $[25,26]$. SOX11 has also been identified as a tumor suppressor gene [27] and improve recurrence-free survival rates in epithelial ovarian cancer [28]. SOX11 could be silenced by methylated modification of SOX11 gene promoter, and then contributes to the development of tumor [29, 30]. Promoter methylation of tumor suppressor gene SOX11 has been reported in various cancerous diseases, including gastric cancer [31], hematopoietic malignancies [29] and nasopharyngeal carcinoma [30]. As such, SOX11 may serve as a biomarker for cancer diagnosis. However, there is no data on the diagnostic potential of serum SOX11 promoter methylation in HCC. This study was therefore aimed to investigate the potential role of serum SOX11 promoter methylation as a noninvasive biomarker in the diagnosis of patients with hepatitis B virus associated HCC.

\section{Materials and methods}

Study population. A total of 205 subjects were retrospectively collected in this study, including 111 patients with HCC, 66 patients with $\mathrm{CHB}$, and 28 healthy controls (HCs), from March 2013 to June 2015 at the Department of Hepatology, Qilu Hospital of Shandong University. HCC patients were diagnosed according to the 2010 update of the American Association for the Study of Liver Diseases (AASLD) Practice Guidelines for Management of HCC [32]. CHB patients were identified as positive hepatitis B surface antigen ( $\mathrm{HBsAg}$ ) for at least 6 months prior to the beginning of this study [33]. The $111 \mathrm{HCC}$ patients and $66 \mathrm{CHB}$ patients in the study were all $\mathrm{HBsAg}$ positive. Exclusion criteria included other tumors, coinfection with hepatitis $C$ virus or human immunodeficiency virus, autoimmune liver diseases, non-alcoholic fatty liver diseases, alcoholic liver diseases and other causes of chronic liver diseases. The selection process of patients is shown in Figure 1. The study protocol was approved by the Ethics Committee of Qilu Hospital of Shandong University and all the subjects have provided informed consents.

Serum DNA extraction and sodium bisulfite modification. Two microliter of serum was isolated from blood by high-speed centrifugal and then stored at $-20^{\circ} \mathrm{C}$ until use. Serum DNA was extracted from $400 \mu \mathrm{L}$ of serum with the QIAamp DNA Blood Mini Kit (Qiagen, Hilden, Germany) following the DNA Purification from Blood or Body Fluids protocol. According to the manufacturer's instructions, extracted DNA was modified using the EZ DNA MethylationGold Kit (Zymo Research, Irvine, CA, United States).

After bisulfite treatment, the methylated residues could resist to this modification and remained as cytosine, whereas, all unmethylated cytosine residues would be converted to uracil. A final volume of $20 \mu \mathrm{L}$ modified DNA was obtained and stored at $-20{ }^{\circ} \mathrm{C}$.

Methylation-specific polymerase chain reaction. The modified DNA samples were amplified with primers specific for both methylated and unmethylated sequences. The primer pairs of SOX11 for MSP analysis were as described previously [31]. MSP was performed in a total volume of $25 \mu \mathrm{L}$ containing $1 \mu \mathrm{L}$ of bisulfite-treated DNA, $0.5 \mu \mathrm{L}$ each primer $(10 \mu \mathrm{mol} / \mathrm{L})$, $12.5 \mu \mathrm{L}$ Premix Taq (Zymo Research), and $10.5 \mu \mathrm{L}$ nucleasefree water. The PCR protocol included initial denaturation at $95^{\circ} \mathrm{C}$ for $10 \mathrm{~min}$, followed by 45 cycles of a denaturation step at $95^{\circ} \mathrm{C}$ for $30 \mathrm{sec}$, an annealing step at $52^{\circ} \mathrm{C}$ for $40 \mathrm{sec}$, an extension step at $72^{\circ} \mathrm{C}$ for $40 \mathrm{sec}$, and a final extension step at $72^{\circ} \mathrm{C}$ for $10 \mathrm{~min}$. The expected size of the bisulfite-specific SOX11 PCR product is $156 \mathrm{bp}$ (Table 1). DNA from normal lymphocytes was used as a negative control. And water without DNA was used as a blank control for contamination. $7 \mu \mathrm{L}$ of PCR products were electrophoresed on 2\% agarose gels, stained with Gel Red, and visualized under UV illumination.

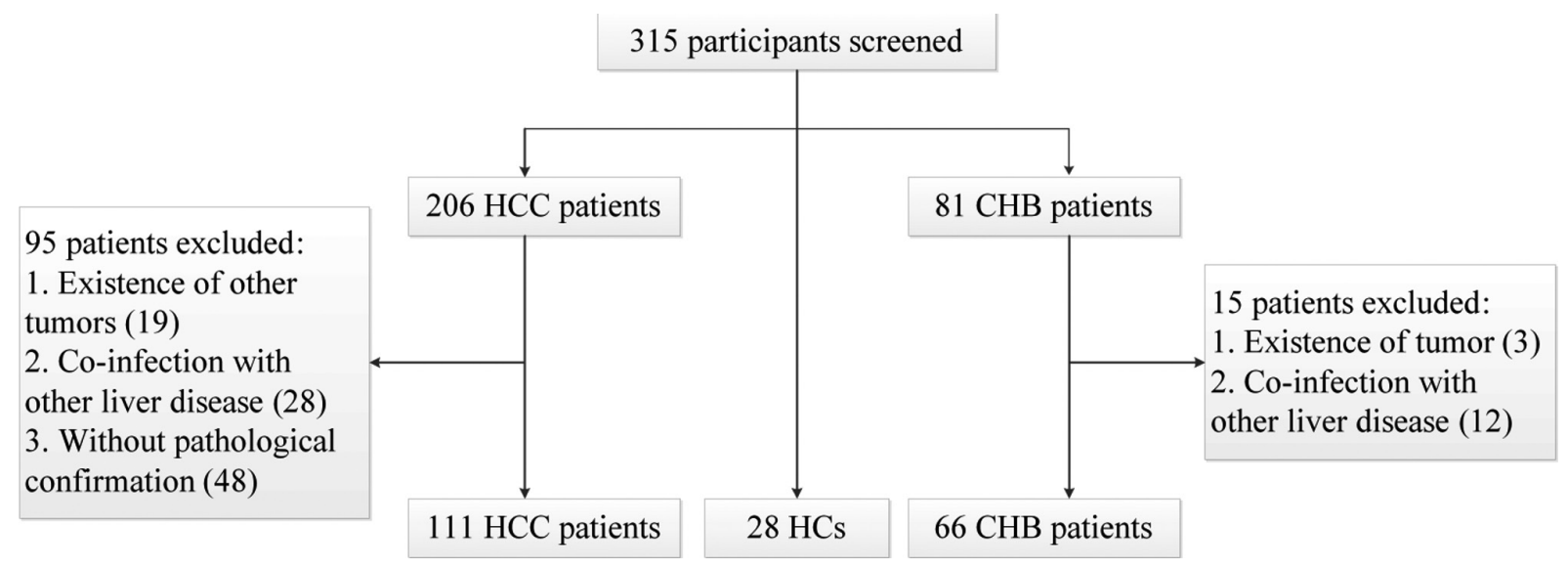

Figure 1. Flowchart depicting the selection process of the participants. 
Table 1. Primer for MSP of the SOX 11 Gene

\begin{tabular}{llcc}
\hline Primer & Primer sequence $\left(5^{`}-3^{c}\right)$ & $\begin{array}{c}\text { Annealing } \\
\text { temp. }\left({ }^{\circ} \mathrm{C}\right)\end{array}$ & $\begin{array}{c}\text { Product } \\
\text { size }(\mathrm{bp})\end{array}$ \\
\hline $\mathrm{U}$ & F: GTTGGGTTATATTAAGTGGTT & 52 & 156 \\
$\mathrm{M}$ & $\begin{array}{l}\text { R: ACAAAATCTTCTCACTATCCT } \\
\text { F: TCGGGTTATATTAAGCGGTC }\end{array}$ & 52 & 156 \\
& R: CGAAATCTTCTCGCTATCCT & & \\
\hline
\end{tabular}

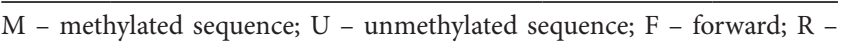
reverse.

Statistical analysis. All statistical analysis was performed using the IBM SPSS 22.0 software (SPSS Inc., Chicago, IL, USA). The $\chi^{2}$ test, and Student's t-test were used to generate $P$ values and $P<0.05$ was considered statistically significant. The difference of serum SOX11 methylation status between different groups were analyzed using the $\chi^{2}$-test. The association between serum SOX11 promoter methylation status of HCC patients and their clinicopathological parameters were analyzed by $\chi^{2}$-test and multivariate logistic regression. The receiver operating characteristic (ROC) curves was made by "Comparison of ROC curves" in MedCalc Statistical Software 11.5.0. The area under the receiver operating characteristic curves (AUC) was used to estimate the diagnostic value of SOX11 gene promoter methylation and AFP level in discriminating $\mathrm{CHB}$ from HCC.

The diagnostic value of AFP, SOX11 methylation and AFP combined with SOX11 methylation was also statistically assessed by sensitivity (Se), specificity (Sp), positive predictive value (PPV) and negative predictive value (NPV). Se is the proportion of positive test in HCC patients; Sp is the proportion of negative test in CHB or HCs; PPV means the proportion of the true positive in the positive group; NPV means the proportion of the true negative in the negative group.

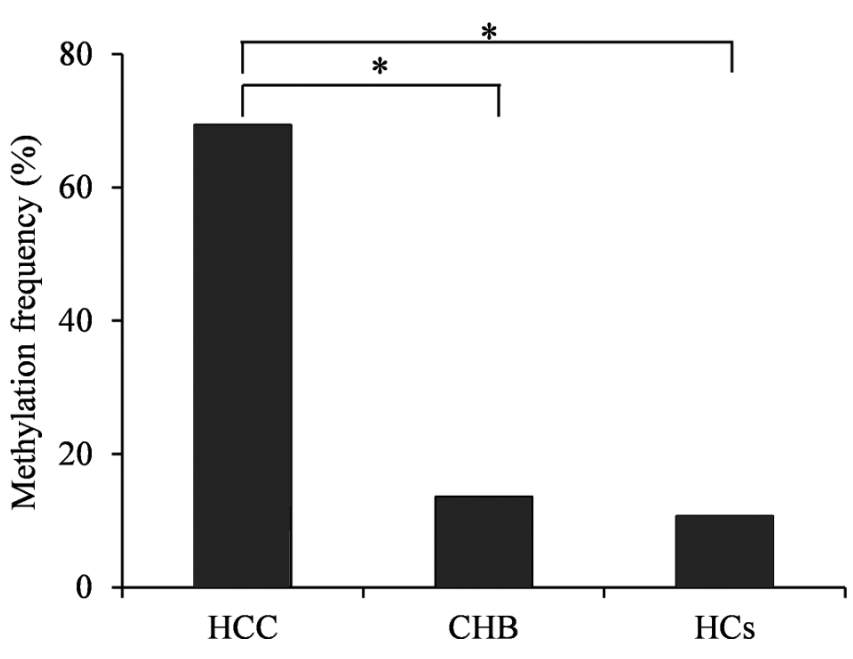

Figure 2. Methylation frequency of SOX11 promoter in the serum from patients with HCC (69.4\%), CHB (13.6\%) and HCs $(10.7 \%) .{ }^{\star} P<0.05$.

\section{Results}

Methylation status of SOX11 promoter in serum. The baseline characteristics of all the subjects were presented in Table 2. Figure.2 demonstrated that methylation of serum SOX11 promoter were detected in 77 of $111(69.4 \%)$ HCC patients, 9 of 66 (13.6\%) CHB patients and 3 of $28(10.7 \%)$ HCs. The frequency of serum SOX11 promoter methylation in HCC patients was significantly higher than that in $\mathrm{CHB}$ patients $\left(\chi^{2}=51.467, P<\right.$ $0.05)$ and HCs $\left(\chi^{2}=31.489, P<0.05\right)$, respectively. However, there were no statistical differences of serum SOX11 promoter methylation between $\mathrm{CHB}$ patients and HCs $\left(\chi^{2}=0.007, P>\right.$ 0.05). Representative agarose gel electrophoresis results for methylated SOX 11 were presented in Figure 3.

Correlation between SOX11 promoter methylation and clinicopathological parameters. Table 3 revealed that the

Table 2. Baseline Characteristics of the Participants

\begin{tabular}{lccc}
\hline Variable & HCC group $(n=111)$ & CHB group $(n=66)$ & HC group $(n=28)$ \\
\hline Age $($ years $)$ & $59(51-64)$ & $47(42-54)$ & $28(25-31)$ \\
Gender $(\mathrm{M} / \mathrm{F})$ & $94 / 17$ & $47 / 19$ & $9 / 19$ \\
HBeAg $(+/-)$ & $26 / 85$ & $28 / 38$ & NA \\
HBsAg & $3553.00(1583.00-5126.00)$ & $4297.50(849.00-5515.00)$ & NA \\
ALT $(\mathrm{U} / \mathrm{L})$ & $43.00(26.00-85.00)$ & $25.00(16.75-45.75)$ & NA \\
AST $(\mathrm{U} / \mathrm{L})$ & $77.00(45.00-147.00)$ & $24.50(19.00-38.25)$ & NA \\
TBIL $(\mu \mathrm{mol} / \mathrm{L})$ & $25.30(14.20-43.30)$ & $12.45(9.55-17.60)$ & NA \\
ALB $(\mathrm{g} / \mathrm{L})$ & $36.10(31.30-40.70)$ & $47.40(45.38-49.63)$ & NA \\
PT-INR & $1.11(1.04-1.34)$ & $1.05(1.00-1.10)$ & NA \\
AFP $(\mathrm{ng} / \mathrm{ml})$ & $51.00(6.13-430.60)$ & $6.69(3.09-32.09)$ & $1.00(0.89-1.35)$ \\
Methylation, $N(\%)$ & $77(69.37 \%)$ & $9(13.63 \%)$ & $3(10.71 \%)$ \\
\hline
\end{tabular}

HCC - hepatocellular carcinoma; CHB - chronic hepatitis B; HC - healthy control; M - male; F - female; ALT - alanine aminotransferase; AST - aspartate aminotransferase; TBIL - total bilirubin; ALB - albumin; PT-INR - prothrombin time-international normalized ratio; AFP - alpha-fetoprotein; NA - not available. 




Figure 3. Representative results for methylation of SOX11 by methylationspecific polymerasechain reaction. A 100-bp DNA ladder marker was used. Lanes $\mathrm{M}$ and $\mathrm{U}$ indicate the amplified products with primers recognizing methylated and unmethylated sequences, respectively. NC, negative control; WB, water blank

serum SOX11 promoter methylation frequency in HCC patients with vascular invasion (49/58) was significantly higher than those without vascular invasion $\left(28 / 53 ; \chi^{2}=13.058\right.$, $P<0.001)$. However, SOX11 promoter methylation status was not significantly associated with gender, age, $\mathrm{HBeAg}$, serum AFP level, alcohol, smoking, tumor number, tumor size, histological grading, or Tumor node metastasis (TNM) staging (all $P>0.05$ ), respectively. In Table 4 , the multivariate logistic regression showed that there were no independent parameters for SOX11 promoter methylation except vascular invasion $(P<0.05)$.

The diagnostic value of SOX11 promoter methylation and combination with AFP in HCC. When trying to discriminate $\mathrm{HCC}$ from $\mathrm{CHB}$ patients, methylation of the serum SOX11 gene promoter showed a sensitivity of $69 \%$

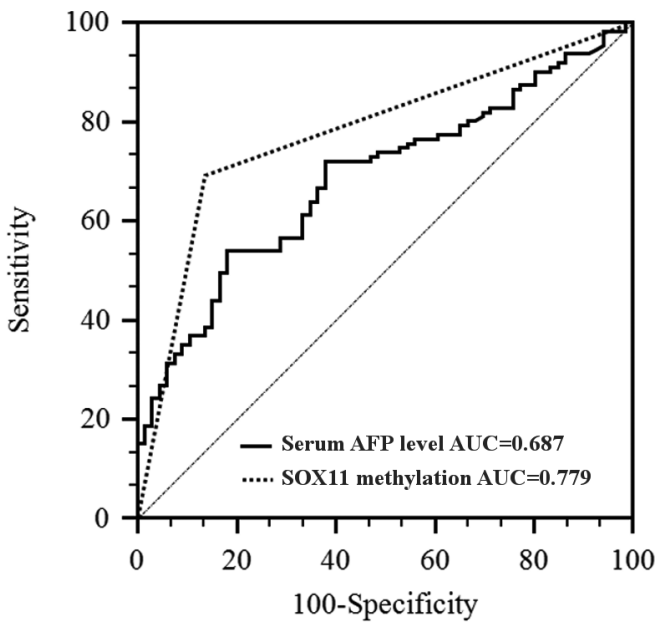

Figure 4. The receiver operating characteristic (ROC) curves of AFP and SOX11 promoter methylation in discriminating $\mathrm{HCC}$ from $\mathrm{CHB}$ patients. Areas under ROC curves between SOX11 promoter methylation and AFP were compared using MedCalc statistical software 11.5.0. Areas under the ROC curve, AUROC.

and a specificity of $86 \%$, and AFP showed a sensitivity of $57 \%$ and a specificity of $66 \%$. Moreover, SOX11 methylation showed a sensitivity of $69 \%(77 / 111)$, a specificity of $89 \%(25 / 28)$ in discriminating HCC from HCs (Table 5). The area under AUC (ROAUC) of serum SOX11 promoter methylation (0.779, 95\% CI: 0.710-0.837) was significantly

Table 3. Clinicopathological Parameters with SOX11 Promotor Methylation in HCC Patients

\begin{tabular}{|c|c|c|c|c|}
\hline \multirow[b]{2}{*}{ Parameters } & \multicolumn{2}{|c|}{ SOX11 methylation status } & \multirow[b]{2}{*}{ Statistics } & \multirow[b]{2}{*}{$P$ value } \\
\hline & Methylated & Unmethylated & & \\
\hline Age & $58.00(51.00-64.00)$ & $59.00(49.75-63.25)$ & $T=-0.534$ & $0.595^{\mathrm{a}}$ \\
\hline Gender $(\mathrm{M} / \mathrm{F})$ & $67 / 10$ & $27 / 7$ & $X^{2}=1.051$ & $0.305^{\mathrm{b}}$ \\
\hline $\operatorname{HBeAg}(-/+)$ & $58 / 19$ & $27 / 7$ & $X^{2}=0.220$ & $0.639^{b}$ \\
\hline Smoking $(-/+)$ & $36 / 41$ & $21 / 13$ & $X^{2}=2.218$ & $0.145^{\mathrm{b}}$ \\
\hline Alcohol $(-/+)$ & $39 / 38$ & $23 / 11$ & $X^{2}=2.764$ & $0.096^{\mathrm{b}}$ \\
\hline Number (single/multiple) & $41 / 36$ & $23 / 11$ & $X^{2}=2.003$ & $0.157^{\mathrm{b}}$ \\
\hline Vascular invasion $(-/+)$ & $28 / 49$ & $25 / 9$ & $X^{2}=13.058$ & $<0.001^{\mathrm{b}}$ \\
\hline AFP & $61.00(4.42-589.14)$ & $39.12(6.21-139.00)$ & $Z=-0.358$ & $0.720^{c}$ \\
\hline Size & & & $X^{2}=0.001$ & $0.970^{\mathrm{b}}$ \\
\hline$\leq 3 \mathrm{~cm}$ & 32 & 14 & & \\
\hline$>3 \mathrm{~cm}$ & 45 & 20 & & \\
\hline Histological grading & & & $X^{2}=2.514$ & $0.285^{\mathrm{b}}$ \\
\hline Poor & 30 & 8 & & \\
\hline Moderate & 30 & 17 & & \\
\hline Well & 17 & 9 & & \\
\hline TNM staging & & & $X^{2}=0.226$ & $0.635^{\mathrm{b}}$ \\
\hline $\mathrm{I} / \mathrm{II}$ & 37 & 18 & & \\
\hline III/IV & 40 & 16 & & \\
\hline
\end{tabular}

$\mathrm{M}$ - male; F - female; TNM - tumor node metastasis.

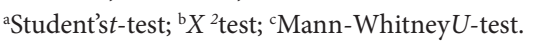


Table 4. Multivariate Logistic Regression Analysis of Clinicopathological Parameters with SOX11 Promoter Methylation in HCC

\begin{tabular}{lcccc}
\hline Variable & Coefficient & OR & $95 \%$ CI & $P$ value \\
\hline Vascular invasion & 2.102 & 8.181 & $1.578-42.407$ & 0.012 \\
Gender & -0.075 & 0.928 & $0.246-3.493$ & 0.912 \\
Age & 0.007 & 1.007 & $0.956-1.060$ & 0.794 \\
HBeAg & 0.21 & 1.233 & $0.379-4.011$ & 0.728 \\
Smoking & 0.035 & 1.035 & $0.354-3.026$ & 0.949 \\
Alcohol & 0.323 & 1.381 & $0.466-4.086$ & 0.560 \\
Number & 0.242 & 1.274 & $0.254-6.398$ & 0.768 \\
Size & -0.127 & 0.881 & $0.320-2.421$ & 0.805 \\
AFP & 0.000 & 1.000 & $1.000-1.000$ & 0.796 \\
Histological grading & -0.034 & 0.966 & $0.493-1.895$ & 0.920 \\
TNM staging & -1.278 & 0.276 & $0.073-1.042$ & 0.057 \\
\hline OR
\end{tabular}

OR - odds ratio; CI - confidence interval

higher than serum AFP (ROAUC $=0.687,95 \%$ CI: 0.613 $0.754 ; P<0.05$; Figure. 4).

Furthermore, we compared the diagnostic value of the combination of the AFP and serum SOX11 methylation with AFP alone in detecting HCC from CHB (Figure 5). As the serum AFP was at the level of less than $20 \mathrm{ng} / \mathrm{ml}$, the HCC detection rate in SOX11 methylated group (32/47, 86\%) was significantly higher than that in SOX11 unmethylated group $(16 / 45,29 \%$; $P<0.05)$. As the serum AFP was at the level of $\geq 20 \mathrm{ng} / \mathrm{ml}$, the frequency of HCC was also significantly higher in SOX11 methylated group $(45 / 49,92 \%)$ than in SOX11 unmethylated
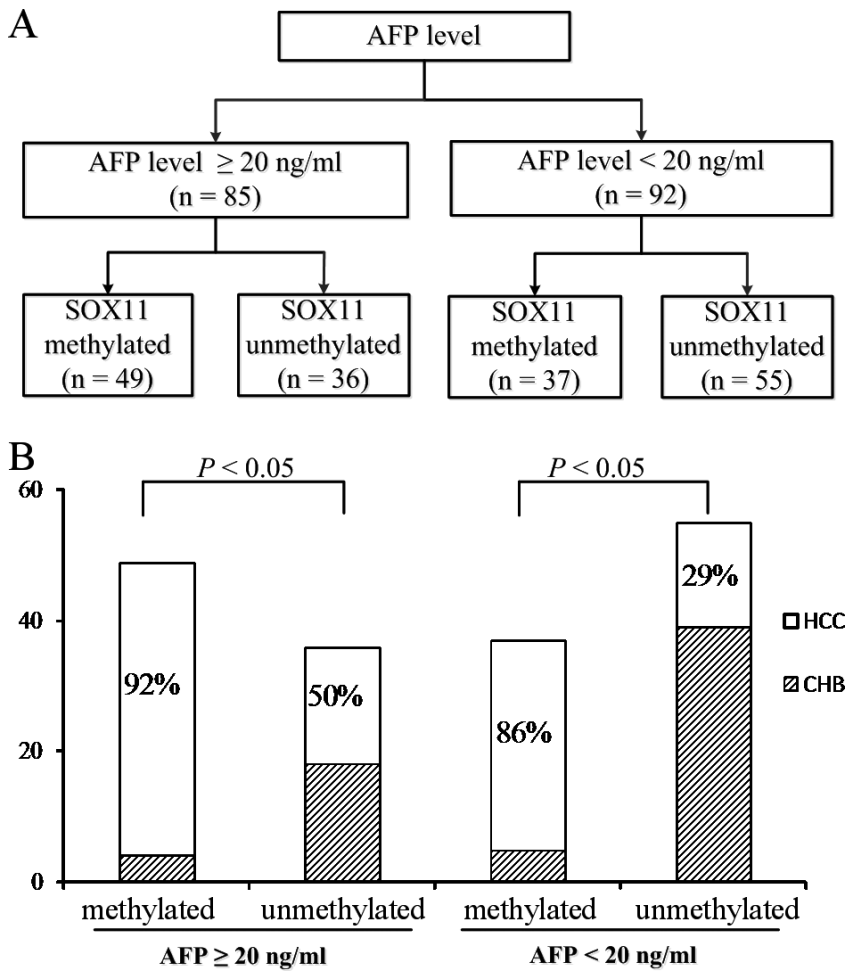

Figure 5. (A). Classification of patients according to serum AFP level and SOX11 promoter methylation. (B). HCC detection rates in methylated and unmethylated group at the AFP cut-off points of $20 \mathrm{ng} / \mathrm{ml} . P$ values refer to the differences of proportion of HCC between methylated and unmethylated group $(P<0.05)$.

Table 5. Diagnostic Value of Serum SOX11 Methylation and AFP in Predicting HCC

\begin{tabular}{|c|c|c|c|c|c|}
\hline & SOX11 methylation & AFP & AFP + SOX11 methylation & Statistic & $P$ value \\
\hline \multicolumn{6}{|l|}{$\mathrm{HCC}$ from $\mathrm{CHB}$} \\
\hline \multicolumn{6}{|l|}{$\mathrm{Se}(\%)$} \\
\hline $\mathrm{TP} /(\mathrm{TP}+\mathrm{FN})$ & 77/111 (69\%) & $63 / 111(57 \%)$ & 95/111 (85\%) & $X^{2}=15.321$ & $<0.05$ \\
\hline \multicolumn{6}{|l|}{$\mathrm{Sp}(\%)$} \\
\hline $\mathrm{TN} /(\mathrm{TN}+\mathrm{FP})$ & $57 / 66(86 \%)$ & $44 / 66(66 \%)$ & $39 / 66(59 \%)$ & $X^{2}=0.811$ & 0.368 \\
\hline \multicolumn{6}{|l|}{ PPV (\%) } \\
\hline $\mathrm{TP} /(\mathrm{TP}+\mathrm{FP})$ & $77 / 86(90 \%)$ & $63 / 85(74 \%)$ & $95 / 122(78 \%)$ & $X^{2}=0.390$ & 0.532 \\
\hline \multicolumn{6}{|l|}{ NPV (\%) } \\
\hline $\mathrm{TN} /(\mathrm{TN}+\mathrm{FN})$ & $57 / 91(63 \%)$ & $44 / 92(48 \%)$ & $39 / 55(71 \%)$ & $X^{2}=7.461$ & $<0.05$ \\
\hline \multicolumn{6}{|l|}{$\mathrm{HCC}$ from $\mathrm{HCs}$} \\
\hline \multicolumn{6}{|l|}{$\operatorname{Se}(\%)$} \\
\hline $\mathrm{TP} /(\mathrm{TP}+\mathrm{FN})$ & 77/111 (69\%) & $63 / 111(57 \%)$ & $95 / 111(85 \%)$ & $X^{2}=15.321$ & $<0.05$ \\
\hline \multicolumn{6}{|l|}{$\mathrm{Sp}(\%)$} \\
\hline $\mathrm{TN} /(\mathrm{TN}+\mathrm{FP})$ & $25 / 28(89 \%)$ & $28 / 28(100 \%)$ & $25 / 28(89 \%)$ & $X^{2}=3.170$ & 0.075 \\
\hline \multicolumn{6}{|l|}{ PPV (\%) } \\
\hline $\mathrm{TP} /(\mathrm{TP}+\mathrm{FP})$ & $77 / 80(96 \%)$ & $63 / 63(100 \%)$ & 95/98 (97\%) & $X^{2}=1.965$ & 0.161 \\
\hline \multicolumn{6}{|l|}{ NPV (\%) } \\
\hline $\mathrm{TN} /(\mathrm{TN}+\mathrm{FN})$ & $25 / 59(42 \%)$ & $28 / 76(37 \%)$ & $25 / 41(61 \%)$ & $X^{2}=6.26$ & $<0.05$ \\
\hline
\end{tabular}

$P$ values refer to the differences between AFP only and combination of AFP and SOX11 methylation. Se (\%), TP/(TP + FN); Sp (\%), TN / (TN + FP); PPV(\%), $\mathrm{TP} /(\mathrm{TP}+\mathrm{FP})$ and NPV (\%), TN / (TN+FN) were calculated and plotted. TP - True positive; FN - False negative; FP - False positive; TN - True negative 
group (18/36, 50\%; $P<0.05)$. In Table 5, we set AFP $\geq 20 \mathrm{ng} \mathrm{ml}$ or SOX11 methylation as positive, and identify 122 patients in patients with $\mathrm{HCC}$ and $\mathrm{CHB}$ as positive including $95 \mathrm{HCC}$ patients (true positive) and $27 \mathrm{CHB}$ patients (false positive). Meanwhile, 55 patients with AFP $<20 \mathrm{ng} / \mathrm{ml}$ and unmethylated SOX11 were set as negative, which containing $39 \mathrm{CHB}$ patients (true negative) and 16 HCC patients (false negative). Therefore, the diagnostic value of SOX11 methylation plus AFP has been calculated with a sensitivity of $85 \%$ (95/111), a specificity of 59\% (39/66), PPV of 78\% (95/122) and NPV of $71 \%(39 / 55)$ in discriminating HCC form CHB. Of note, the sensitivity $\left(\chi^{2}=15.321, P<0.05\right)$ and NPV $\left(\chi^{2}=7.461, P<\right.$ $0.05)$ are significantly higher than AFP alone, respectively. In addition, SOX11 alone showed a sensitivity of $69 \%$ (77/111), a specificity of $89 \%$ (25/28), PPV of $96 \%$ (77/80) and NPV of $42 \%(25 / 59)$ in discriminating HCC from HCs. SOX11 plus AFP has been calculted with a sensitivity of $85 \%(95 / 111)$, a specificity of $89 \%$ (25/28), PPV of $97 \%$ (95/98) and NPV of $61 \%(25 / 41)$ in discriminating HCC form HCs.

\section{Discussion}

To our knowledge, this present study was the first report to determine the potential value of serum SOX11 promoter methylation as a noninvasive biomarker for the diagnosis of HCC. Our results showed that the serum SOX11 methylation frequency was significant higher in $\mathrm{HCC}$ compared with $\mathrm{CHB}$ and HCs. We also reported that SOX11 promoter methylation was significantly associated with vascular invasion in HCC patients. Furthermore, we demonstrated that SOX11 promoter methylation showed higher diagnostic accuracy than APF alone in discriminating HCC from CHB. SOX11 promoter methylation might improve the diagnostic accuracy of AFP in the diagnosis of HCC. Therefore, our results strongly suggested that serum SOX11 promoter methylation might serve as a useful and noninvasive biomarker for the diagnosis of HCC.

The transcription factor SOX11 plays an important role in regulating cell differentiation, proliferation and survival in the pathogenesis of tumor $[25,26]$. SOX11 gene could be epigenetically silenced through DNA methylation, which results in the down-regulation of SOX11 protein $[29,30]$. Several studies showed that SOX11 methylation existed in gastric cancer [31], hematopoietic malignancies [29], and nasopharyngeal carcinoma [30]. In our study, we found that the SOX11 methylation rate was obviously higher in HCC patients than in both $\mathrm{CHB}$ and HCs, indicating the potential role of SOX11 in the pathogenesis of HCC. We also found a strong relationship between SOX11 methylation and vascular invasion. The results agreed with Zhang's study that SOX11 methylation might contribute to the growth and invasion of nasopharyngeal carcinoma [30]. In HCC patients, the possible association between methylation and invasion might be explained from the following aspects: First, SOX11 has been demonstrated as a tumor suppressor gene and could be transcriptional inactivation mediated by promoter methylation [34]. The methylation silienced SOX11 expression might therefore result in the growth and invasion of tumor cells [30]. Second, tumor-derived mutant DNA in situ tissue might migrate into peripheral circulation and then lead to the detectable level of serum SOX11 promoter methylation [13,35].

Until now, methylation abnormalities of some specific genes in the serum have been used as biomarkers in the diagnosis of HCC, such as IGFBP7 [13], RASSF1A [21] P15 and P16 $[20,22]$. In this present study, we demonstrated that SOX11 showed potential diagnostic value with high sensitivity and specificity in the diagnosis of hepatitis B virus-related HCC. Our study also compared the combination of AFP and SOX11 methylation with AFP alone in discriminating HCC patients from CHB patients. The sensitivity increased to $85 \%$ (combination of two markers) from 57\% (AFP alone). Also, the NPV is higher in combination of two markers $(39 / 55,71 \%)$ than AFP alone (44/92, 48\%). Notably, the specificity of SOX11 promoter methylation alone in detecting HCC was $86 \%$ but significantly decreased to $59 \%$ when combined with AFP with a $20 \mathrm{ng} / \mathrm{ml}$ cut-off value. Therefore, our results suggest that the methylation of serum SOX11 promoter can improve the sensitivity of AFP in diagnosis of HCC. Meanwhile, serum SOX11 methylation may be applied to ensure a rather low false-positive rate in detecting HCC.

However, there are some limitations in our study. First, the MSP method we used is just a qualitative method to identify whether methylation occurs or not. Other methods, such as direct sequencing, might provide more exact and detailed information to determine methylation. However MSP can be performed in most clinical laboratories easily and rapidly. Although MSP is not very informative, we can still use it to select methylated cases that could be further examined. Second, the patients were from our single unit and data from a multi-center, large-scale cohort would be more helpful.

In conclusion, our study demonstrated that SOX11 promotor methylation could be frequently detected in the serum of patients with HCC. Furthermore, SOX11 promotor methylation might be a useful noninvasive biomarker for diagnostic of HCC. Combination of AFP and serum SOX11 promotor methylation could enhance the sensitivity of AFP alone in the diagnostic of HCC.

Acknowledgements: This work was supported by the grants from the Key Project of Chinese Ministry of Science and Technology (2012ZX10002007, 2013ZX10002001), National Natural Science Foundation of China $(81171579,81201287,81371832)$, Science and Technology Development Plan of Shandong Province (2014GSF118068).

\section{References}

[1] MCGLYNN KA, PETRICK JL, LONDON WT. Global epidemiology of hepatocellular carcinoma: an emphasis on demographic and regional variability. Clin Liver Dis 2015; 19: 223-238. http://dx.doi.org/10.1016/i.cld.2015.01.001 
[2] WAGHRAY A, MURALI AR, MENON KN. Hepatocellular carcinoma: From diagnosis to treatment. World J Hepatol 2015; 7: 1020-1029. http://dx.doi.org/10.4254/wjh. v7.i8.1020

[3] Srivatanakul P, Sriplung H, Deerasamee S. Epidemiology of liver cancer: an overview. Asian Pacific journal of cancer prevention : APJCP 2004; 5: 118-125.

[4] MALUCCIO M, COVEY A. Recent progress in understanding, diagnosing, and treating hepatocellular carcinoma. CA: A Cancer Journal for Clinicians 2012; 62: 394-399. http:// dx.doi.org/10.3322/caac. 21161

[5] SCHAFER DF, SORRELL MF. Hepatocellular carcinoma. Lancet 1999; 353: 1253-1257. http://dx.doi.org/10.1016/ $\underline{\text { S0140-6736(98)09148-X }}$

[6] ATTWA MH, EL-ETREBY SA. Guide for diagnosis and treatment of hepatocellular carcinoma. World J Hepatol 2015; 7: 1632-1651. http://dx.doi.org/10.4254/wjh.v7.i12.1632

[7] DEMASI S, TOSTI M, MELE A. Screening for hepatocellular carcinoma. Digestive and Liver Disease 2005; 37: 260-268. http://dx.doi.org/10.1016/j.dld.2004.11.005

[8] JALLI R, JAFARI SH, SEFIDBAKHT S, KAZEMI K. Comparison of the Accuracy of DWI and Ultrasonography in Screening Hepatocellular Carcinoma in Patients With Chronic Liver Disease. Iran J Radiol 2015; 12: e12708.

[9] FARINATI F, MARINO D, DE GIORGIO M, BALDAN A, CANTARINI $M$, et al. Diagnostic and prognostic role of alpha-fetoprotein in hepatocellular carcinoma: Both or neither? American Journal of Gastroenterology 2006; 101: 524-532. http://dx.doi.org/10.1111/j.1572-0241.2006.00443.x

[10] GIANNINI EG, MARENCO S, BORGONOVO G, SAVARINO V, FARINATI F, et al. Alpha-fetoprotein has no prognostic role in small hepatocellular carcinoma identified during surveillance in compensated cirrhosis. Hepatology 2012; 56: 1371-1379. http://dx.doi.org/10.1002/hep.25814

[11] KIM H, KIM K, JIN J, PARK J, YU SJ, et al. Measurement of Glycosylated Alpha-Fetoprotein Improves Diagnostic Power over the Native Form in Hepatocellular Carcinoma. Plos One 2014; 9. http://dx.doi.org/10.1371/journal.pone.0110366

[12] COLLI A, FRAQUELLI M, CASAZZA G, MASSIRONI S, COLUCCI A, et al. Accuracy of ultrasonography, spiral CT, magnetic resonance, and alpha-fetoprotein in diagnosing hepatocellular carcinoma: A systematic review. American Journal of Gastroenterology 2006; 101: 513-523. http://dx.doi. org/10.1111/j.1572-0241.2006.00467.x

[13] LI F, FAN Y-C, GAO S, SUN F-K, YANG Y, et al. Methylation of serum insulin-like growth factor-binding protein 7 promoter in hepatitis B virus-associated hepatocellular carcinoma. Genes, Chromosomes and Cancer 2014; 53: 90-97. http:// dx.doi.org/10.1002/gcc. 22120

[14] JONES PA, BAYLIN SB. The fundamental role of epigenetic events in cancer. Nature Reviews Genetics 2002; 3: 415-428.

[15] JONES PA, BAYLIN SB. The Epigenomics of Cancer. Cell 2007; 128: 683-692. http://dx.doi.org/10.1016/j.cell.2007.01.029

[16] KANEDA A, KAMINISHI M, YANAGIHARA K, SUGIMURA T, USHIJIMA T. Identification of silencing of nine genes in human gastric cancers. Cancer Research 2002; 62: 6645-6650.
[17] ILIOPOULOS D, GULER G, HAN S-Y, JOHNSTON D, DRUCK T, et al. Fragile genes as biomarkers: epigenetic control of WWOX and FHIT in lung, breast and bladder cancer. Oncogene 2005; 24: 1625-1633. http://dx.doi.org/10.1038/ sj.onc. 1208398

[18] NAKAYAMA M, GONZALGO ML, YEGNASUBRAMANIAN S, LIN X, DE MARZO AM, et al. GSTP1 CpG island hypermethylation as a molecular biomarker for prostate cancer. Journal of Cellular Biochemistry 2004; 91: 540-552. http://dx.doi.org/10.1002/jcb.10740

[19] TAMURA G, YIN J, WANG S, FLEISHER AS, ZOU TT, et al. E-cadherin gene promoter hypermethylation in primary human gastric carcinomas. Journal of the National Cancer Institute 2000; 92: 569-573. http://dx.doi.org/10.1093/ jnci/92.7.569

[20] ZHANG YJ, WU HC, SHEN J, AHSAN H, TSAI WY, et al. Predicting Hepatocellular Carcinoma by Detection of Aberrant Promoter Methylation in Serum DNA. Clinical Cancer Research 2007; 13: 2378-2384. http://dx.doi. org/10.1158/1078-0432.CCR-06-1900

[21] YEO W, WONG N, WONG W-L, LAI PBS, ZHONG S, et al. High frequency of promoter hypermethylation of RASSF1A in tumor and plasma of patients with hepatocellular carcinoma. Liver International 2005; 25: 266-272. http://dx.doi. org/10.1111/j.1478-3231.2005.01084.x

[22] WONG IHN, LO YMD, YEO W, LAU WY, JOHNSON PJ. Frequent $\mathrm{p} 15$ promoter methylation in tumor and peripheral blood from hepatocellular carcinoma patients. Clinical Cancer Research 2000; 6: 3516-3521.

[23] LIEW CT, LI HM, LO KW, LEOW CK, CHAN JYH, et al. High frequency of p16(INK4A) gene alterations in hepatocellular carcinoma. Oncogene 1999; 18: 789-795. http://dx.doi. org/10.1038/sj.onc.1202359

[24] WONG IHN, LO YMD, ZHANG J, LIEW CT, NG MHL, et al. Detection of aberrant p16 methylation in the plasma and serum of liver cancer patients. Cancer Research 1999; 59: 71-73.

[25] PENZO-M NDEZ AI. Critical roles for SoxC transcription factors in development and cancer. The International Journal of Biochemistry \& Cell Biology 2010; 42: 425-428. http:// dx.doi.org/10.1016/j.biocel.2009.07.018

[26] WEGNER M. All purpose Sox: The many roles of Sox proteins in gene expression. The International Journal of Biochemistry \& Cell Biology 2010; 42: 381-390. http://dx.doi.org/10.1016/j. biocel.2009.07.006

[27] SERNBO S, GUSTAVSSON E, BRENNAN DJ, GALLAGHER WM, REXHEPAJ E, et al. The tumour suppressor SOX11 is associated with improved survival among high grade epithelial ovarian cancers and is regulated by reversible promoter methylation. BMC Cancer 2011; 11: 405. http://dx.doi. org/10.1186/1471-2407-11-405

[28] BRENNAN DJ, EK S, DOYLE E, DREW T, FOLEY M, et al. The transcription factor Sox 11 is a prognostic factor for improved recurrence-free survival in epithelial ovarian cancer. European Journal of Cancer 2009; 45: 1510-1517. http:// dx.doi.org/10.1016/j.ejca.2009.01.028

[29] GUSTAVSSON E, SERNBO S, ANDERSSON E, BRENNAN DJ, DICTOR M, et al. SOX11 expression correlates to 
promoter methylation and regulates tumor growth in hematopoietic malignancies. Mol Cancer 2010; 9: 187. http://dx.doi. org/10.1186/1476-4598-9-187

[30] ZHANG S, LI S, GAO JL. Promoter methylation status of the tumor suppressor gene SOX11 is associated with cell growth and invasion in nasopharyngeal carcinoma. Cancer Cell Int 2013; 13: 109. http://dx.doi.org/10.1186/1475-2867-13-109

[31] XU X, CHANG X, LI Z, WANG J, DENG P, et al. Aberrant SOX11 promoter methylation is associated with poor prognosis in gastric cancer. Cellular Oncology 2015; 38: 183-194. http://dx.doi.org/10.1007/s13402-015-0219-7

[32] YAZICI C, NIEMEYER DJ, IANNITTI DA, RUSSO MW. Hepatocellular carcinoma and cholangiocarcinoma: an up- date. Expert Review of Gastroenterology \& Hepatology 2014; 8: 63-82. http://dx.doi.org/10.1586/17474124.2014.852468

[33] LOK ASF, MCMAHON BJ. Chronic hepatitis B: Update 2009. Hepatology 2009; 50: 661-662. http://dx.doi.org/10.1002/ hep. 23190

[34] LYKO F, BROWN R. DNA Methyltransferase Inhibitors and the Development of Epigenetic Cancer Therapies. JNCI Journal of the National Cancer Institute 2005; 97: 1498-1506. http://dx.doi.org/10.1093/jnci/dji311

[35] DIEHL F, SCHMIDT K, CHOTI MA, ROMANS K, GOODMAN S, et al. Circulating mutant DNA to assess tumor dynamics. Nature Medicine 2007; 14: 985-990. http://dx.doi. org/10.1038/nm.1789 